Wiame, J. M., Harpigny, R. \& Dothey, R. G. (1959). J. gen. Microbiol. 20, 165-172.

\title{
A New Type of Acetobacter: Acetobacter acidophilum prov. sp.
}

\author{
BY J. M. WIAME, R. HARPIGNY AND R. G. DOTHEY \\ Service de Recherches du Centre d'Enseignement et de Recherches des Industries \\ Alimentaires et Chimiques (C.E.R.I.A.), Bruxelles, and Laboratoire de \\ Microbiologie de l'Université Libre de Bruxelles, Belgique
}

SUMMARY: A new type of Acetobacter, provisionally named Acetobacter acidophilum, has been isolated in pure culture from an experimental vinegar generator originally inoculated with active industrial beechwood shavings. In contrast to other bacteria, this organism needs an acidic medium for growth and has a very specific oxidizing capacity. It does not grow above $\mathrm{pH} 4 \cdot 3$ and oxidizes only primary alcohols. Other substrates, including glucose and acetic acid, are not oxidized at a rate higher than $1 \%$ of the oxidation rate for ethanol. The new isolation procedure, which has been applied for the strain described in this paper, allows the isolation of the bacteria present on active shavings, suggesting that this type of bacteria belongs probably to the group of organisms responsible for the acetification in the 'quick vinegar process'.

The microbiology of the industrial production of vinegar by the most common procedure, the so-called 'quick vinegar process', is still very obscure. Although not very often explicitly stated, the difficulty of isolating bacteria from the beechwood shavings, as well as from the liquid of the vinegar generator, is well known. This is the reason that prompted us to investigate this problem. These difficulties could hamper the solution of an interesting problem of bacterial ecology, which is of some practical importance.

The bacteria called by Henneberg (1926) the 'Schnellessigbakterien' (Acetobacter acetigenum, $A$. schützenbachi and $A$. curvum) were believed by this author to be the organisms which are responsible for the process. The opinion of Henneberg has been repeated uncritically in some treatises on industrial microbiology. Recent works on Acetobacter have not included studies of these species. They are either neglected or relegated to mere listing in the appendix (Bergey's Manual, 1948, 1957). In Frateur's monograph (1950), the three species of Henneberg are not included for lack of sufficient description and, as mentioned by Frateur, the bacteria of the quick process remained an enigma. These Acetobacter are not identical with the known species, since they do not grow on the classical solid media. It has been possible to isolate Acetobacter from beechwood shavings, but always after an enrichment. In different media, such as beer, mineral media, after 1 week or more of immersion to half height of a shaving, some growth occurs and bacteria may be isolated by plating on yeast water + ethanol $+\mathrm{CaCO}_{3}$ agar (Frateur, 1950). This method is not free of the pitfalls of selection inherent in this sort of isolation. The isolated organisms represent only a small proportion of the initial bacteria. In any event, it would have been necessary to test the isolated bacteria on a sterile 
experimental quick vinegar apparatus (3rd Koch postulate). For these reasons, we have avoided enrichment cultures. All efforts at isolation in neutral media were unsuccessful. However, the use of solid media containing yeast extract + ethanol acidified to $\mathrm{pH} \mathbf{4 . 5}$ with acetic acid resulted in the growth of extremely small colonies, almost invisible to the naked eye. The results were, however, very irregular and it was difficult to transfer the bacteria from plate to plate. With this material, and also with the method of purification by extreme dilution, we were able to inoculate an experimental acidifier loaded with woodwool and a sterile medium similar to the one used in industry (Wiame \& Lambion, 1950; Lambion \& Wiame, 1951). An acidity of $11 \%$ $(w / v)$ of acetic acid was obtained after 25 days. In spite of such results, the difficulty of obtaining colonies and their successful transfer remained the main obstacle for a rational study of the bacteria.

After many attempts to improve the growth on solid medium, we tried an acid medium ( $\mathrm{pH} \mathrm{3 \cdot 0)}$ ) solidified by an acid-resistant gel. The result was very striking: small but workable colonies were observed, allowing us to study more carefully the physiology of this organism which is very different from Acetobacter organisms studied hitherto. By the procedure described in this paper it has been possible to obtain colonies regularly by directly plating material from shavings. However, this paper pertains only to one strain, leaving for further study the comparison of new strains isolated directly from industrial apparatus. At least, the properties of this organism explain the difficulties encountered in previous work. It is hoped that their elucidation will help to resolve the enigma of this very old industrial process.

\section{METHODS}

\section{Isolation of Acetobacter acidophilum on solid medium}

Since the organism has an optimal $\mathrm{pH}$ of $\mathbf{3 \cdot 0 - 3 \cdot 2}$ and grows slowly, it is difficult to solidify the medium with agar. The silica gel method of Winogradsky was used with success and gave visible colonies (Pl. 1, fig. 1). This method is cumbersome and, for this reason, we tried a new silica gel method proposed by Kingsbury \& Barghoorn (1954). It consists in the use of a commercial colloidal suspension of silicic acid which, after mixture with the nutrient medium, is solidified by autoclaving. For the present purpose, we proceeded as follows.

The commercial colloidal silica product (Ludox, Dupont de Nemours and Co., Inc., Wilmington, Delaware, U.S.A.) was de-ionized on the two resins Amberlite IR 120 and Amberlite IR 45. The Amberlite IR 120 was used in the acid form and, when necessary, regenerated by passing two volumes of $\mathbf{M - H C l}$. The Amberlite IR 45 was used in the basic form and regenerated by two volumes of $\mathrm{NaOH} 4 \%(\mathrm{w} / \mathrm{v})$. The resins after regeneration and washing with distilled water were always dried by suction in order to keep the product undiluted by the de-ionization procedure. The Ludox had an initial $\mathrm{pH}$ value of 10. This product was mixed with one volume of Amberlite IR 120; by filtration the Ludox was obtained at $c . \mathrm{pH} 2$ and was mixed with one volume of Amberlite IR 45; after filtration, the $\mathrm{pH}$ value was $c .4 \cdot 5$. This product was 
used for the next step. One volume of each resin may be used for two or three volumes of Ludox, before regeneration.

The de-ionized Ludox was mixed with the liquid nutrient, in the proportion of 6.25 to $3 \cdot 75(\mathrm{v} / \mathrm{v})$. After mixing, the final concentrations of ingredients of the medium were: yeast extract, $0.5 \%(\mathrm{w} / \mathrm{v})$, acetic acid, $3 \%(\mathrm{w} / \mathrm{v})$, ethanol, $4 \%(\mathrm{v} / \mathrm{v})$ and minerals (see liquid medium); the $\mathrm{pH}$ value was $\mathbf{3 \cdot 2}$.

The mixture was poured into Petri dishes which were placed horizontally in the autoclave. The temperature was raised slowly; after $15 \mathrm{~min}$. at $110^{\circ}$, the temperature was brought down slowly again. When the gel was well formed it was easy to use a thick platinum wire for inoculation. It was necessary to begin by the addition of a few drops of sterile water to the suspension of bacteria; dry plates at the start in general failed to grow. The plates were kept in a container which received a short flush of $\mathrm{CO}_{2}$ (see later, requirement for $\mathrm{CO}_{2}$ ). To avoid the formation of cracks in the gel after drying, it was best, after a few days, to seal the plates with paraffin. Slopes of silica gel can be made similarly. The bacteria remained viable for a long time under these conditions. The colonies grew slowly to a diameter of $0.5 \mathrm{~mm}$., becoming denser and slightly brown. Illustrations of young colonies are given in $\mathrm{Pl}$. 1, figs. 2, 3. The edge of a colony is shown in $\mathrm{Pl}$. 1, fig. 4 .

\section{Growth in liquid medium}

The following medium was used routinely: ethanol, $4 \%(\mathrm{v} / \mathrm{v})$; glacial acetic acid, $3 \%$ (w/v); yeast extract (Difco), $0.5 \%$ (w/v); $\left(\mathrm{NH}_{4}\right)_{2} \mathrm{SO}_{4}, 0.002 \mathrm{M} ; \mathrm{K}_{2} \mathrm{SO}_{4}$, $0.002 \mathrm{M} ; \mathrm{KH}_{2} \mathrm{PO}_{4}, 0.002 \mathrm{M} ; \mathrm{MgSO}_{4}, 0.0002 \mathrm{M}$; ferric citrate, $2 \cdot 10^{-6} \mathrm{M}$. The ethanol was added after sterilization. The cultures were incubated at $30^{\circ}$ in $40 \mathrm{ml}$. volumes of this medium dispensed in conical flasks of $125 \mathrm{ml}$. capacity. The cultures were aerated on a rotating shaker (120-140 rev./min.). After the sterilization of such an acid medium, it was found necessary to introduce a small quantity of $\mathrm{CO}_{2}$ into the gas-phase to help start the growth. To keep the cultures in the active growing phase, $4 \mathrm{ml}$. culture were transferred every $48 \mathrm{hr}$. After $48 \mathrm{hr}$. the cultures reached an opacity of about $0 \cdot 2-0 \cdot 3$ scale unit, when measured in a Spekker opacimeter, with $1 \mathrm{~cm}$. light path. One $\mathrm{ml}$. of a culture of optical density 1.0 corresponded to a dry weight of $0.25 \mathrm{mg}$; $1 \mathrm{mg}$. dry weight corresponded to $0.11 \mathrm{mg}$. $/ \mathrm{N}$. When the growth was followed, special flasks with a cylindrical side arm were used (Wiame \& Storck, 1953). Aeration was obtained by using a magnetic stirrer. When a special gas-phase composition was needed, an injection of gas was done by a tube passing through the cottonwool plug.

\section{RESULTS}

\section{Some characteristics of the organism}

The Acetobacter acidophilum organisms are elongated, single, in pairs or at times in chains of four to five rods. Plate 2, fig. 5, shows the organism under phase contrast. The bacteria were not motile and electron microscopy did not show any evidence of flagella, even when the bacteria were grown directly on the 
films used for the preparation. Plate 2, figs. 6, 7, show the bacteria after growth in liquid medium. The electron micrograph revealed a rough appearance of the bacterial surface. The rods were unusually opaque to the electron beam. Treatment with ultrasonic waves for $15 \mathrm{~min}$. (Raytheon $10 \mathrm{Kc}$.) broke the organisms into smaller pieces, but did not result in a marked decrease in opacity as occurs with other bacteria, e.g. Bacillus subtilis and Escherichia coli. The organisms in the active growing phase were Gram negative and the catalase test negative.

\section{Effect of acidity and nutrients}

Figures 1 and 2 show that the bacteria only grew at $\mathrm{pH}$ values $2 \cdot 7$ and $4 \cdot 0$. The best growth was obtained at pH 3.0-3.5 and no growth occurred above $4 \cdot 3$. This was true not only when the acidity was produced by acetic acid, but also with phosphoric acid.

The absolute quantity of acetic acid + acetate affected the growth. Growth was very limited when the molarity of the mixture was higher than 0.5 (Fig. 3). It is mainly with respect to this property that other strains should be studied.

As previously mentioned, the organism requires a complex medium, e.g. containing generally $0.5 \%(\mathrm{w} / \mathrm{v})$ yeast extract. With decreasing concentrations of yeast extract the growth decreased both in rate and total growth. The addition of guanine was slightly beneficial. All attempts to replace the yeast extract with defined mixtures have up to now failed; these included: the addition of folic acid, biotin, $p$-aminobenzoic acid, riboflavin, nicotinic acid, pyridoxine and pantothenic acid. Guanine, uracil and adenine alone, or in mixtures with other vitamins or casein hydrolysate, did not support growth.

\section{Influence of $\mathrm{CO}_{2}$}

Upon sterilization of the acid medium the loss of $\mathrm{CO}_{2}$ led to very irregular results. It was then observed that successful growth depended on the size of the neck of the flask, suggesting the need for the $\mathrm{CO}_{2}$ of the atmosphere. This was tested by alternate depletion and addition of the $\mathrm{CO}_{2}$ (Fig. 4). Depletion was done by passing the air through two gas-washers with $\mathrm{NaOH}$, $10 \%(\mathrm{w} / \mathrm{v})$. The gas was then introduced into the atmosphere of the vessel through the cotton plug. The addition of $\mathrm{CO}_{2}$ corresponded to $c .1 \%(\mathrm{v} / \mathrm{v})$ of the air inflow. The need for $\mathrm{CO}_{2}$ in such a complex medium was unexpected, since the use of yeast extract has very often been shown to obviate the need for $\mathrm{CO}_{2}$ (Lwoff, Audureau \& Monod, 1947; Ajl \& Werkman, 1948). In the present case, it seems that the need for $\mathrm{CO}_{2}$ is not required for synthesis of amino acids derived from the tricarboxylic acids (Wiame \& Bourgeois, 1955; Wiame, 1957), which are present in the yeast extract. Addition of all the members of the tricarboxylic acid cycle had no effect. Preliminary studies on the utilization of $\mathrm{CO}_{2}$ show that it is not found mainly in glutamic or aspartic acids, but in compounds tentatively identified as the basic amino acids. 


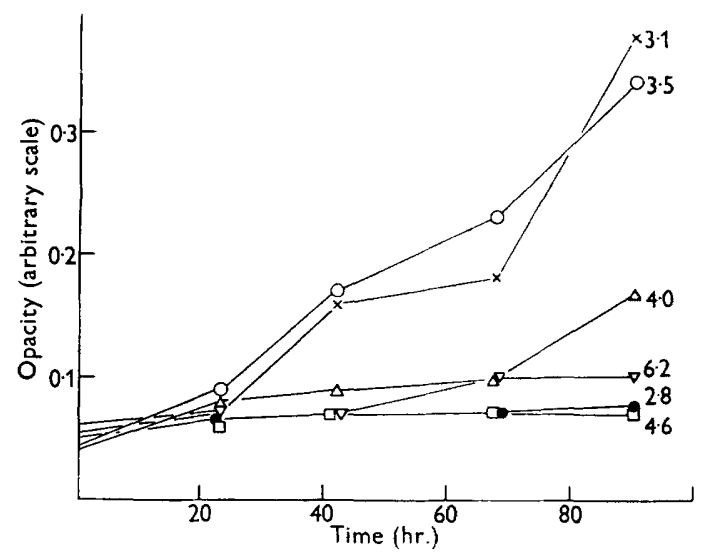

Fig. 1. Influence of acidity (acetic acid) on growth. Growth in liquid medium (see Methods) adjusted to different $\mathrm{pH}$ values, by $\mathrm{NaOH}\left(10 \%\right.$, w/v) or $\mathrm{H}_{3} \mathrm{PO}_{4}, 0.04 \mathrm{M}$. Aeration by magnetic stirrer and continuous introduction of air. The numbers given on the curves indicate the initial $\mathrm{pH}$ values of the cultures.

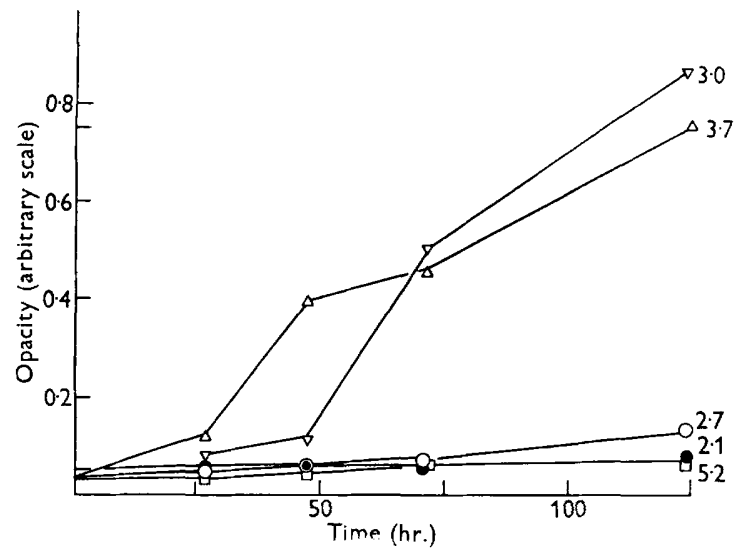

Fig. 2

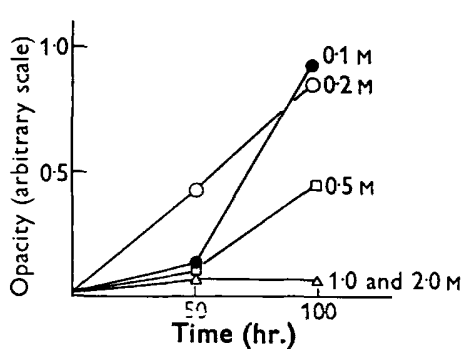

Fig. 3

Fig. 2. Influence of acidity (phosphoric acid) on growth. As in Fig. 1, but the acetic acid of the medium was replaced by mixtures of $\mathrm{KH}_{2} \mathrm{PO}_{4}+\mathrm{H}_{3} \mathrm{PO}_{4}$ (final concentration $0.3 \mathrm{M}$ ). The numbers given on the curves indicate the initial $\mathrm{pH}$ values of the cultures.

Fig. 3. Effect of the total quantity of acetic acid + acetate. The $\mathrm{pH}$ value was kept constant at $3 \cdot 1$. The total concentration of acetic acid + acetate was variable. Liquid medium, as previously, was used.

\section{Oxidative capacities}

All simple primary alcohols from $\mathrm{C}_{2}$ to $\mathrm{C}_{5}$ were oxidized at a considerable rate (Fig. 5). The oxidation stopped when an equivalent of acid was formed. Methanol was not oxidized. Isobutanol was not oxidized at the same rate as the normal alcohol. Among the secondary alcohols, isopropanol was slowly oxidized. Primary alcohols containing other groups, such as glycol and glycerol, were not oxidized.

With a suspension of organism which had an oxidative capacity of $4200 \mu \mathrm{l}$. $\mathrm{O}_{2} / \mathrm{hr}$./mg. $\mathrm{N}$ for ethanol, the value for the oxidation of glucose was only 17 . 
The following substances or mixtures were not oxidized at a measurable rate: acetic acid (40 and $10 \mu \mathrm{mole} /$ vessel), lactic acid, pyruvic acid, $\alpha$-keto glutaric acid, citric acid, succinic acid, malic acid (10 $\mu$ mole/vessel). Endogenous respiration was not higher than the experimental error and there was no $\mathrm{O}_{2}$ consumption with yeast extract alone or with acetic acid. The feeble oxidation

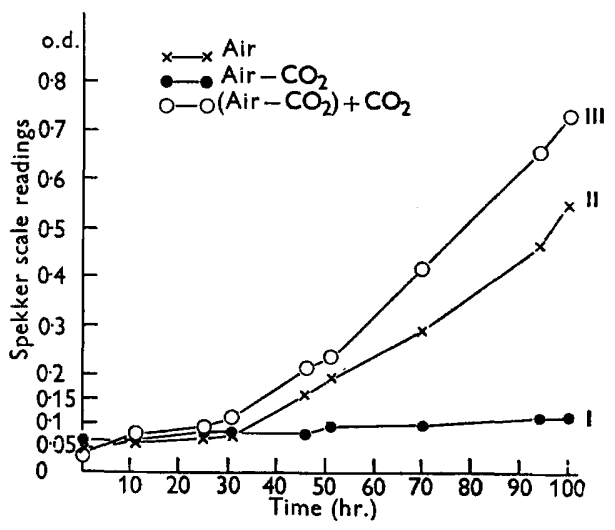

Fig. 4

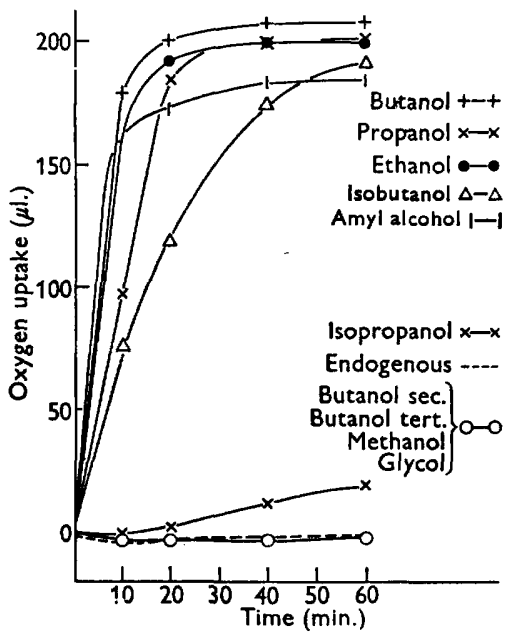

Fig. 5

Fig. 4. Effect of $\mathrm{CO}_{2}$ on the growth of Acetobacter acidophilum. A freshly sterilized medium was used and the atmosphere kept constant by injections of gas mixtures. Curve I, air passed through $\mathrm{NaOH}$; curve II, ordinary air; curve III, air, after being deprived of $\mathrm{CO}_{2}$, with subsequent addition of pure $\mathrm{CO}_{2}(c .1 \%)$.

Fig. 5. Oxidation of alcohols by $A$. acidophilum at $30^{\circ}$, tested by the standard manometric method, $10 \mu$ mole of all substrates. The main cup contained $2 \mathrm{ml}$. of a suspension of bacteria corresponding to $0.26 \mathrm{mg}$ of bacterial nitrogen in phosphate buffer $0.04 \mathrm{M}$, pH $3 \cdot 1 \cdot 0 \cdot 2 \mathrm{ml} .5 \mathrm{~N}-\mathrm{NaOH}$ was placed in the centre well. All substances were commercial products, analytical grade, without further purification. The break in the oxidation of amyl alcohol was probably due to the presence also of a branched-chain amyl alcohol.

of glucose was unexpected for an Acetobacter. Modification in $\mathrm{pH}$ value $(3 \cdot 1-6 \cdot 5)$ did not change significantly the oxidation of glucose or acetic acid. Acetobacter ascendens (Henneberg) and A. peroxydans (Visser 't Hooft) are other types which do not oxidize glucose. All the tests reported here were done after growth on ethanol in the presence of acetic acid; it is not excluded that some substrates might be oxidized after suitable adaptation.

The oxidation of ethanol, in contrast to growth, was not depressed at $\mathbf{p H} 5$ or even at 6.5. In the acid range, at $\mathrm{pH} 3 \cdot 1,3 \%(\mathrm{w} / \mathrm{v})$ acetic acid depressed the rate of oxidation by about $50 \%$, and $7 \%$ acetic acid decreased the oxidative capacity to $25 \%$ of that obtained at $\mathrm{pH} 3 \cdot 1$ in phosphoric buffer $(0 \cdot 04 \mathrm{M})$.

\section{DISCUSSION}

From the results reported here it is easy to understand the difficulty which has been encountered in previous attempts to isolate bacteria such as Acetobacter acidophilum. The strain described in this work may be a 'domesticated' 
one, since it was isolated in an experimental apparatus, but, as said earlier, other strains may be isolated by direct plating and these are now under study. The striking properties of this organism permit the prediction that this type of Acetobacter is the active bacterium of the 'quick vinegar process'. Other strains may be more or less resistant to high concentrations of acetic acid. By using classical microbiological methods it should be easy to start new studies of many strains and to select those best adapted for industrial applications. The recent use of the submerged culture technique might also be improved in this way (Hromatka \& Ebner, 1949, 1950).

It is interesting to note the unique character of our organism, in particular its acidophily as well as its very restricted oxidation ability. The organism most resistant to acid, Thiobacillus thiooxidans, can still grow at $\mathrm{pH} 6 \cdot 0$. Acetobacter acidophilum shows a type of physiology corresponding to a very specialized ecological habitat. If one tries to place this organism in the at present accepted classification of Acetobacter, one is confronted with the difficulty of using the present criteria, since these bacteria do not grow under the proposed conditions. However, our organism is a typical acetic acid bacterium, perhaps the most specialized one, since its best characteristic is the oxidation of ethanol to acetic acid and its growth obligately in an acidic medium. The lack of catalase might place it in the 'peroxydans' group, but this seems to be in opposition to its limited oxidative capacity.

We propose the species Acetobacter acidophilum as a provisional name to be examined by taxonomists. Our feeling is that this organism owes its identity not so much to the presence or lack of a specialized set of enzymes, but to a very specialized interaction with the external medium.

What we have said about Acetobacter acidophilum does not exclude the fact that bacteria of very different types might be important in some industrial vinegar processes; our study concerns only bacteria which originated from one factory. The question of the bacteria involved in the 'quick vinegar process' was reviewed by Shimwell (1954). This author succeeded in the isolation by plating of an organism able to carry out good acidification. These bacteria were isolated on an ordinary medium and were able to grow in the presence of $\mathrm{CaCO}_{3}$ on many different media. They possessed the characteristics of A. mesoxydans, as described by Frateur (1950), and are very different from A. acidophilum.

It is proposed to deposit this culture with the National Collection of Industrial Bacteria, Teddington, England.

This work was supported by the Union Belge des Vinaigriers and the Institut pour l'Encouragement de la Recherche Scientifique dans l'Industrie et l'Agriculture (I.R.S.I.A.). We owe to the Vinaigrerie l'Etoile and to its Director the late Mr R. Dothey, not only the material, but also the encouragement to examine this industrial problem.

A short report on this subject was given at the Congrès International du Vinaigre, La Haye, May 1957, by J. M. Wiame, R. G. Dothey and R. Harpigny. 


\section{REFERENCES}

AJu, S. J. \& Werkman, C. H. (1948). Replacement of $\mathrm{CO}_{2}$ in heterotrophic metabolism. Arch. Biochem. 19, 483.

Bergey's Manual of Determinative Bacteriology (1948). 6th edition. Ed. by Breed, R. S., Murray, E. G. D. \& Hitchens, A. P. Baltimore: The Williams and Wilkins Company.

Bergey's Manual of Determinative Bacteriology (1957). 7th edition. Ed. by Breed, R. S., Murray, E. G. D. \& Smith, N. R. Baltimore: The Williams and Wilkins Company.

Frateur, J. (1950). Essai sur la systématique des acetobacters. Cellule, 53, 287.

Henneberg, W. (1926). Handbuch der Gärungsbakteriologie. Berlin: Paul Parey.

Hromatka, O. \& Ebner, H. (1949). Untersuchungen über die Essiggärung. I. Fesselgärung und Durchlüftungsverfahren. Enzymologia, 13, 369.

Hromatka, O. \& Ebner, H. (1950). Untersuchungen über die Essiggärung. II. Sauerstoffmangel der Fesselgärung. Enzymologia, 14, 96.

Kingsbury, J. M. \& Barghoorn, E. S. (1954). Silica gel as a microbiological medium: potentialities and a new method of preparation. Appl. Microbiol. 2, 5.

Lambion, R. \& Wiame, J. M. (1951). Cultures pures d'acetobacter dans les conditions d'acétification rapide. Rev. Ferment. 6, 25.

Lwoff, A., Audureau, A. \& Monod, J. (1947). Essais d'analyse du rôle de l'anhydride carbonique dans la croissance microbienne. Ann. Inst. Pasteur, 73, 323.

Shimweld, J. L. (1954). Pure culture vinegar production. J. Inst. Brew. 60, 136.

Wiame, J. M. (1957). Le rôle biosynthétique du cycle des acides tricarboxyliques. Advanc. Enzymol. 18, 241.

Wiame, J. M. \& Bourgeors, S. (1955). Le rôle de l'anhydride carbonique dans les croissances bactériennes. Biochim. biophys. Acta, 18, 269.

Wiame, J. M. \& Lambion, R. (1950). Contribution à l'étude des acetobacters de vinaigrerie du type 'rapide'. Rev. Ferment. 5, 209.

Wiame, J. M. \& Storck, R. (1953). Métabolisme de l'acide glutamique chez Bacillus subtilis. Biochim. biophys. Acta, 10, 268.

\section{EXPLANATION OF PLATES}

Plate 1

Fig. 1. Colonies of Acetobacter acidophilum on Winogradsky silica gel medium.

Fig. 2. Microscope view of young colonies of $A$. acidophilum on solid media made of Ludox $(\times 110)$.

Fig. 3. Microscope view of very young colonies of $A$. acidophilum on solid media made of Ludox $(\times 220)$.

Fig. 4. Edge of a colony of A. acidophilum ( $\times 440)$.

\section{Plate 2}

Fig. 5. Phase contrast aspect of the bacteria $(\times 770)$.

Fig. 6. Electron microscope photograph of $A$. acidophilum after growth in liquid medium, washing, fixation in formol.

Fig. 7. Electron microscope photograph of A. acidophilum (as Fig. 6).

(Received 26 August 1958) 
Journal of General Microbiology, Vol. 20, No. 1
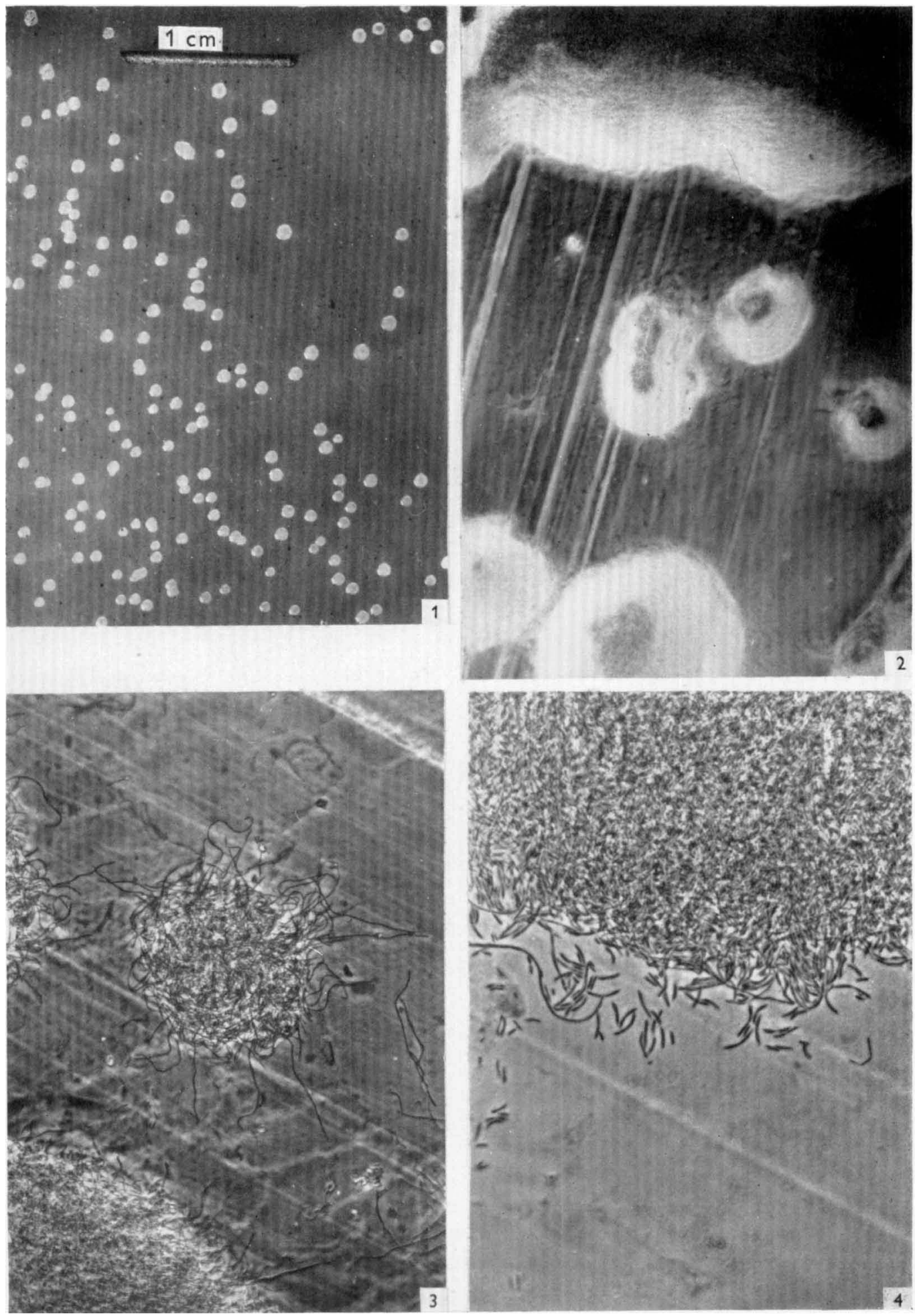

J. M. Wiame, R. Harpigny \& R. G. Dothey-A Nliw type of Acetobicter. PLATE 1 
Journal of General Microbiology, Vol. 20, No. 1

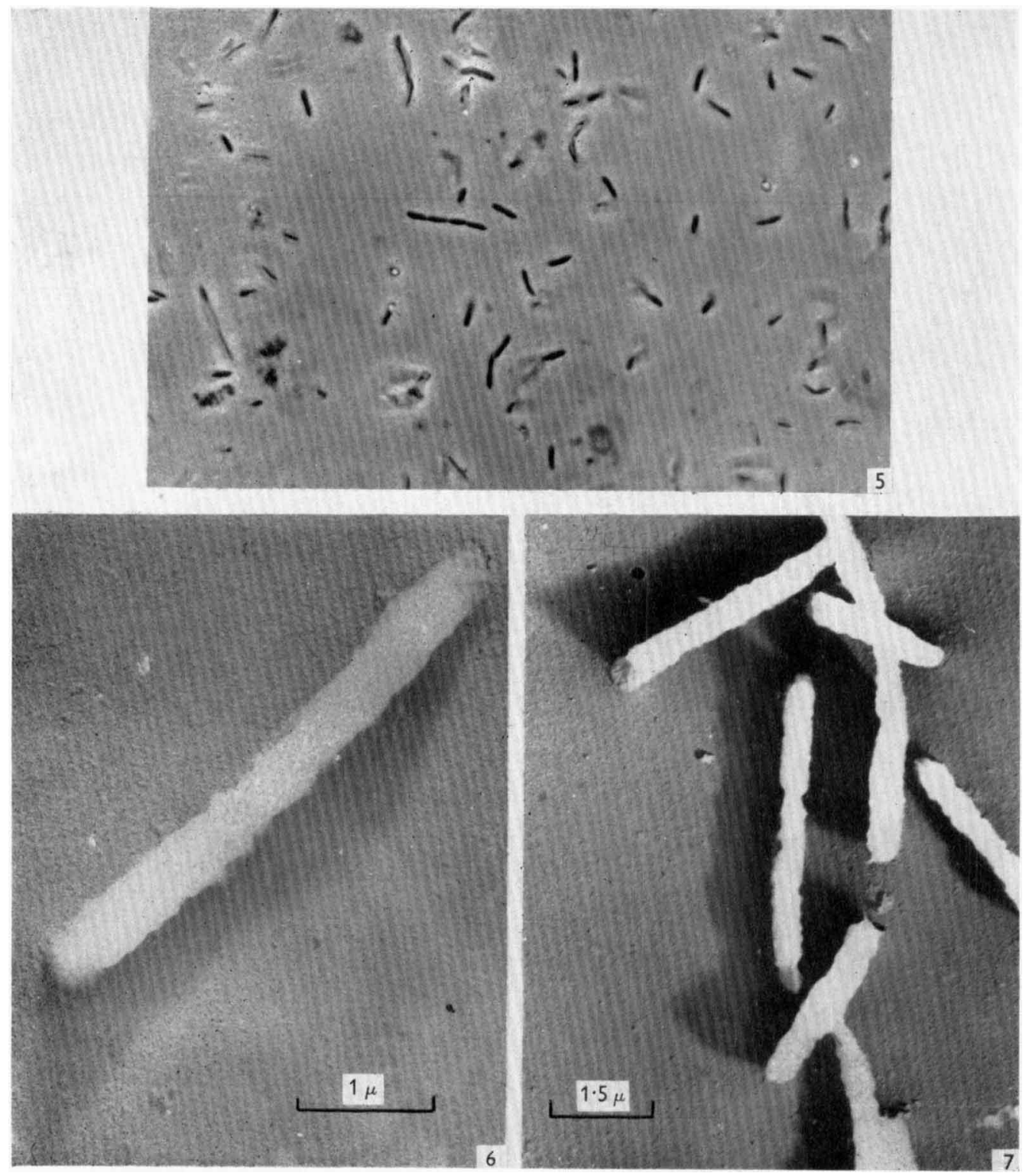

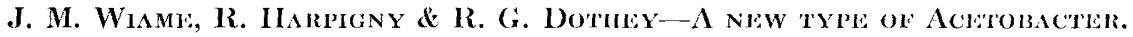
Plate 2 